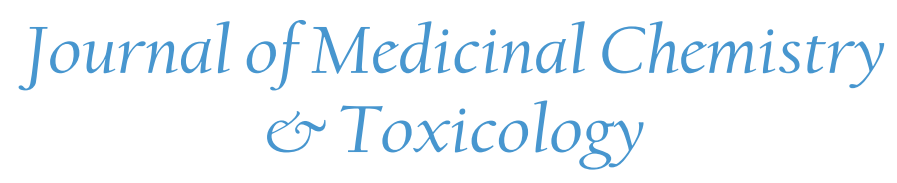

\title{
Pesticide Residues in Food Grains, Vegetables and Fruits: A Hazard to Human Health
}

\author{
Ajmer Singh Grewal ${ }^{1 *}$, Ashish Singla ${ }^{1}$, Pradeep Kamboj ${ }^{1}$, Jagdeep Singh Dua ${ }^{2}$ \\ ${ }^{1}$ Jan Nayak Ch. Devi Lal Memorial College of Pharmacy, Sirsa, 125055, Haryana, India \\ ${ }^{2}$ Shivalik College of Pharmacy, Nangal, 140126, Punjab, India
}

*Corresponding authors: Ajmer Singh Grewal, Jan Nayak Ch. Devi Lal Memorial College of Pharmacy, Sirsa, 125055, Haryana, India; Tel: +91-9416700430; E-mail: ajmergrewal2007@gmail.com

\begin{abstract}
Pesticides are widely used in agriculture mainly to increase crop yields to cater huge supply of food products for increasing world population as well as to protect crops from pests and control insect-borne diseases. Increased use of pesticides results in contamination of the environment and the excess accumulation of pesticide residues in food products, which has always been a matter of serious concern. Pesticide residues in food and crops aredirectly related to the irrational application of pesticides to the growing crops. Accumulated pesticide residues in food products have been associated with a broad variety of human health hazards, ranging from short-term effects to longterm toxic effects. The preventive measures for pesticide residues in the developing countries are limited due to a shortage of funds and lack of defined government regulations. The impact of pesticide residues can be minimized by taking certain measures such as the rational use of pesticides, promoting organic farming, exploit natural and bio pesticides, and proper implementation and amendment of pesticide-related laws. The present article has been planned to review various aspects of pesticide residues including their accumulation in food products, impact on human health, and the preventive measures to counter their toxic effects.
\end{abstract}

Received Date: February 12, 2017

Accepted Date: March 12, 2017

Published Date: March 20, 2017

Citation: Grewal, A.S., et al. Pesticide Residues in Food Grains, Vegetables and Fruits: A Hazard to Human Health. (2017) J Med Chem Toxicol 2(1): 40- 46.

DOI: $10.15436 / 2575-808 X .17 .1355$

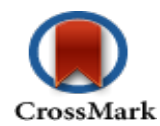

Keywords: Hazards; Human health; Natural pesticides; Organic farming; Organophosphates; Pesticides; Pesticide residues

\section{Introduction}

The term pesticide covers a broad variety of compounds including insecticides, fungicides, herbicides, rodenticides, molluscicides, nematicides, plant growth regulators and others $^{[1]}$. Depending on the chemical structure pesticides can be classified as organochlorines (endosulfan, hexachlorobenzene), organophosphates (diazinon, omethoate, glyphosate), carbamic and thiocarbamic derivatives, carboxylic acids and their derivatives, urea derivatives, heterocyclic compounds (benzimidazole and triazole derivatives), phenol and nitro phenol derivatives, hydrocarbons, ketones, aldehydes and their derivatives, fluorine containing compounds, copper-containing compounds, metal organic and inorganic compounds, and natural and synthetic pyrethroids $^{[2]}$. Ever since the origin of civilization, it has been the major task of man to engage in a continuous endeavor to improve his living conditions. One of the main tasks in which human beings have been engaged is securing relief from hunger. Secondly, the control of insects, weeds, fungi and other pests of economic or public health is of utmost importance to our government ${ }^{[3]}$. Pesticides have consistently revealed their worth through increased agriculture productivity, reduced insect-borne, endemic diseases and protection as well as restoration of plantations, forests, harvested wood products, homes and fiber ${ }^{[4]}$. Currently, pesticides are very valuable in developing nations, particularly those in tropical are as looking for an entry in the global economy by providing off-season fresh vegetables and fruits to nations in more temperate weathers. However, these goals cannot be achieved without the increased use of pesticides, 
mainly insecticides, herbicides and fungicides ${ }^{[5]}$. Ideal pesticides must act selectively against certain pest organisms without adverse effects to non-target organisms. However, it is difficult to achieve absolute selectivity and most pesticides are also toxic to humans and other non-target organisms. Pesticide use raises a number of environmental worries, including human and animal health hazards. Food products contaminated with toxic pesticides are associated with severe effects on the human health. More than $95 \%$ of sprayed insecticides and herbicides reach a destination other than their target species, including non-target species, air, water and soil ${ }^{[6]}$. Pesticide contamination of both surface and ground waters can affect aquatic animals and plants, as well as human health when water is used for public consumption $^{[7]}$. The increased use of chemical pesticides has resulted in contamination of the environment and also caused many associated long-term effects on human health. Pesticides have been associated with a wide spectrum of human health hazards, ranging from short-term impacts such as headaches and nausea to chronic impacts like cancer, reproductive harm and endocrine disruption ${ }^{[8]}$. Pesticide residues in food and crops are a direct result of the application of pesticides to crops growing in the field, and to a lesser extent from pesticide residues remaining in the soil ${ }^{[9]}$. The present work has been planned to review various aspects of pesticide residues including accumulation of pesticide residues in food grains and various hazards to human health due to pesticide residues as well as preventive measures for the minimization of the impact of pesticide residues on human health.

\section{Pesticide residues in food grains, vegetables, and fruits}

Pesticide residue refers to the pesticides or metabolic products of the pesticides that may remain in food grains, vegetables and fruits after they are applied to crops. Many of these chemical residues, especially derivatives of chlorinated pesticides, exhibit bioaccumulation which could build up to harmful levels in the body as well as in the environment ${ }^{[10]}$. Persistent chemicals can be magnified through the food chain and have been detected in products ranging from meat, poultry, and fish, to vegetable oils, nuts, and various fruits and vegetables ${ }^{[11]}$. Insects and pests can cause a loss in the quality and quantity of grains and their products. The application of pesticide is widely used for grains before harvest and after harvest to protect the grains from damage or loss. Cultivation and storage of grains often require an intensive use of pesticides, which may then be found in grains and in foods prepared from them ${ }^{[12]}$. Cereal grains are treated with degradable pesticides, including organophosphates, carbamate, synthetic pyrethroids and insect growth regulators, both in storages and prior to shipment in order to prevent insect infestation ${ }^{[13]}$. The most consumed pesticides for vegetables, fruits and food grains in India include sulphur, endosulfan, mancozeb, phorate, methyl parathion, monocrotophos, cypermethrin, isoproturon, chlorpyrifos, malathion, carbendazim, butachlor, quinalphos, copper oxychloride, and dichlorvos (Source: http:// indiaforsafefood.in). Maximum residue level is the highest level of a pesticide residue that is legally tolerated in or on food or feed when pesticides are applied correctly. International parties such as the European Union, Codex Alimentarius Commission, and North American Free Trade Agreement have attempted to harmonize pesticide legislation by providing maximum residue limits, but globally these limits remain variable. In India, Food Safety and Standards Authority of India sets the maximum resi- due limits for pesticides in crops, foods, vegetables and fruits ${ }^{[14]}$. The Food and Agriculture Organization and World Health Organization have recommended residue limits for bioresmethrin, bromophos, Carbaryl, chlorpyrifos-methyl, deltamethrin, dichlorvos, etrimfos, fenitrothion, fenvalerate, malathion, methacrifos, permethrin, phenothrin, pirimiphosmethyl and pyrethins used for the protection of grains ${ }^{[15]}$. The study in Poland revealed that out of 380 samples of the cereal grains, 34\% were found to contain pesticide residues ${ }^{[16]}$. According to their investigation out of the analyzed cereals, the smallest amount of plant protection products residues was in mixed cereal grains (below 10\%) and Avena grains (below 15\%) whereasHordeum and Triticum grains contained the highest content of pesticide residues (over $50 \%$ ). A study in Nigeria on organochlorine pesticide residues in cereal grains showed the presence of aldrin, dichloran, dieldrin, endrin, endosulfan, heptachlor epoxide, dichlorodiphenyltrichloroethane lindane, methoxychlor, and mirex ${ }^{[17]}$. A study in Pakistan on pesticide residue of cereals showed that wheat contained the highest concentration of tested pesticides than maize and rice and maize contained a much higher concentration of pesticides than rice ${ }^{[18]}$. The accumulation of pesticide residues depends on the physiochemical properties of the pesticide molecules as well as food ${ }^{[19]}$. The use of pesticides during production often leads to the presence of pesticide residues in fruits and vegetables after harvest. Most farmers and commercial producer streat vegetables and fruit with pesticides on several occasions during growing because pesticides decrease toxins produced by food infecting organisms, increase productivity and are less labor intensive. According to a study, the cucumber was the crop with the highest number of pesticide residues with the predominant presence of methomyl, metalaxyl, and imidacloprid. Methomyl is a carbamate insecticide with restricted use because of its high toxicity to humans. The other pesticide residues found in cucumber samples were boscalid, chlorpyrifos, cyprodinil, fenhexamid, imidacloprid, metalaxyl and tebuconazole ${ }^{[20]}$. Many commodities contained more than one residue per product, up to 9 residues in grapes and tea were determined, up to 5 - 9 residues in citrus fruits like orange, mandarins, lemons, peaches, pears and up 3 - 5 residues in pomegranates, plums, cucumbers, tomatoes, strawberries. The most frequently detected pesticide residues were imazalil, thiabendazole, chlorpyrifos, maneb group, procymidone, methidathion, lambda-cyhalothrin, carbendazim, iprodione, orthophenylphenol, vinclozolin, endosulfan, pyrimethanil, fenhexamid, prochloraz, cyprodinil, boscalid. Apples, papayas, sweet peppers and strawberries were among products with the highest percentage of samples with residues above the maximum residue limit found in the Brazilian pesticide residues monitoring program. High level of pesticide residues in pears, grapes, citrus fruit, peppers, cucumbers, tomatoes, carrots were obtained in Lithuania ${ }^{[21]}$. A study in Belgium revealed that pesticide residues were detected in $72 \%$ of the samples and standards were exceeded for $6 \%$ of the samples ${ }^{[22]}$. High level of pesticide residues was determined in imported blackberries, strawberries and other berries as well as mangoes, papaya, pepinos, bitter melon, peas, beans, eggplant, spinach and other vegetables. The commodities with the highest level of pesticide residues found in China were cabbage, legumes and leaf mustard ${ }^{[23]}$. The insecticide residues reported in market samples of grapes were acephate, methamidophos, chlorpyriphos, monocrotophos and quinalphos ${ }^{[24]}$. The residues of lambda-cyhalothrin in acid 
lime were persisted for 20 days and in juice samples maximum residues were observed for 10 days ${ }^{[25]}$. A study on analysis of pesticide residue concentration in vegetables revealed that the risk to consumers varies with the season and it was reported that the winter season has the highest pesticide concentration in vegetables ${ }^{[26]}$. A study on the levels of pesticides in soft drinks available in the market indicates pesticide residues 24 times higher than Bureau of Indian Standards (BIS) norms. The levels of pesticide residue lindane exceeded the BIS standards by 140 times in some samples. Heptachlor, which banned in India, was found in 71 per cent of the samples, at levels four times higher than BIS standards. Chlorpyrifos was found 200 times more than the BIS standard in a sample manufactured in Thane. The average amount of pesticide residues found in all the samples was 24 times higher than the BIS standards for total pesticides in soft drinks (Source: The Hindu). Organochlorine pesticides, mainly isomers of hexachlorohexane, dichloro-diphenyl-trichloroethane, endosulphan, endrin, aldrin, dieldrin, and heptachlore, were identified from potable water samples collected from all over India ${ }^{[2]}$.

\section{Toxic effects of pesticide residues on human health}

Many pesticides achieve their intended use of killing pests by disrupting the nervous system. Due to similarities in brain biochemistry among many different organisms, there is much assumption that these chemicals can have a negative impact on humans as well[ ${ }^{[28]}$. There are epidemiological studies that show positive correlations between exposures to pesticides through occupational hazard, which tends to be significantly higher than that ingested by the general population through food, and the occurrence of certain cancers ${ }^{[29]}$. Although most of the general population may not expose to a large portion of pesticides, many of the pesticide residues that are attached tend to be lipophilic and can bio-accumulate in the body ${ }^{[11]}$. Toxic effects of pesticides depend upon their toxicological properties, the level of residues and degree of exposure of human beings to residues. The presence of pesticide residues in grains does not necessarily mean that it is hazardous. To be toxic, the residues have to be present in quantities large enough to be considered unsafe ${ }^{[30]}$. The organophosphate, organochlorine and related pesticides act by binding to the enzyme acetylcholinesterase, disrupting nerve function, resulting in paralysis and may cause death ${ }^{[31]}$. They may produce acute effects manifesting as meiosis, urination, diarrhea, diaphoresis, lacrimation, excitation of central nervous system and salivation. The chronic exposure in volvesneurotic and behavioral effects. Specific effects of pesticides can include damage to the central and peripheral nervous systems, cancer, allergies and hypersensitivities, reproductive disorders and disruption of the immune system ${ }^{[32]}$.

Neuronal damage due to cholinergic neuronal excitotoxicity and dysfunction: Following exposure to organophosphates, accumulation of acetylcholine at synapses results in rapid and profound excitotoxicity and dysfunction of cholinergic neurons in the brain. Overstimulation of muscarinic acetylcholine receptors may also disrupt the balance of excitatory and inhibitory mechanisms to cause neuronal excitotoxic lesions leading to seizures and respiratory depression ${ }^{[33]}$. Seizures may result from over release of glutamate from glutamatergic neurons, triggering excessive calcium release in post-synaptic neuronal cells ${ }^{[34]}$.
Seizures caused by cholinergic neuronal excitotoxic lesion in the brain may play a synergistic role in development of irreversible brain damage and long-term neurological and behavioural disorder $^{[35]}$. Therapeutic intervention to control the convulsions is unable to halt progressive neural injury and neuronal cell death caused by organophosphate poisoning ${ }^{[36]}$. Secondary neuronal damage is an indirect consequence of the initial lesion and a major contributor to the ultimate neuronal cell death and neural loss in the injured brain leading to serious neuropsychiatric impairments, including memory loss, inability to concentrate, speech problems, motor and sensory deficits, and behavioural problems ${ }^{[37]}$. In the first few hours after organophosphate poisoning, as the result of the cholinergic neuronal excitotoxicity, extensive intracellular edema, cerebral hemorrhages, intracellular calcium overload, oxidative stress and increased neuro inflammatory responses were generally observed in the affected brain regions ${ }^{[38-42]}$. The altered calcium influx activates lipases, proteases, kinases, phosphatases, and endonucleases in potentially harmful metabolic cascades, thus arresting protein synthesis and depriving cells of enzymes or trophic factors essential to their survival ${ }^{[43]}$. Many studies have demonstrated that obvious neuronal cell death, neural loss, and axonal degeneration were observed in different species of animals exposed to organophosphates $^{[44]}$.

\section{Long-term neuropsychiatric and neurological disorders:} Exposure to organophosphates involve damage to cholinergic neurons of basal forebrain and the limbic system, which may cause memory, cognitive, mental, emotional, motor and sensory deficits by disrupting this putative sensory-limbic gating mechanism $^{[45]}$. In 1991, US soldiers were exposed to sarin and cyclosarin when two large chemical ammunition caches were destroyed at Khamisiyah, Iraq during the Gulf War ${ }^{[46]}$. The Gulf War-deployed veterans exposed to sarin and cyclosarin were reported to be suffering from neurological and neuropsychiatric disorders ${ }^{[47]}$. In 1995, a Japanese cult and terrorist organization carried out the sarin gas attack at multiple locations in the Tokyo subway ${ }^{[48]}$. Of the 5500 victims who sought emergency medical care, approximately 1000 were moderately poisoned, 50 were severely poisoned, 47 were certified as disabled, and 12 died due to respiratory failure ${ }^{[49]}$. Many victims could recover from acute cholinergic symptoms of sarin poisoning within a couple of weeks, but mental sequelae lasted for years ${ }^{[50]}$. These chronic neuropsychiatric consequences are serious public health problems caused by accidental and suicidal organophosphate poisonings and chemical terrorist attacks, which result in the losses of many years of productive life and incur large healthcare costs ${ }^{[38]}$.

Persistent memory and cognitive deficits: Memory and cognitive deficits are one of the most common and persistent behavioral sequelae in victims exposed to organophosphates. Exposure to organophosphatessarin and cyclosarin at Khamisiyah resulted in long-term cognitive and memory impairments in the Gulf War-deployed veterans in $1991^{[47]}$. Chronic memory and cognitive impairments were also observed in the victims ofthe Tokyo subway sarin attack ${ }^{[51]} .7$ years after the Tokyo subway sarin attack, a chronic decline of memory function still existed in 23 subway workers exposed to sarin. The exposed subway workers performed less well in the memory function tests, and their digit number of the backward digit span test was signifi- 
cantly smaller ${ }^{[38]}$. Loss of cholinergic neurons in the basal forebrain with aging results in a decline in cognitive capacity ${ }^{[52]}$.

Psychomotor performance deficits and somatic complaints: Clinical study has demonstrated that the Gulf War-deployed veterans exposed to sarin and cyclosarin at Khamisiyah suffered impaired fine psychomotor dexterity, reduced visuospatial abilities and deficits in motor function and coordination ${ }^{[47]}$. After the Tokyo subway sarin attack, a chronic decline of psychomotor function existed in 23 subway workers exposed to sarin for 7 years. The high-exposure subway workers had a significantly slower performance of the finger tapping tests of both the dominant and non-dominant hands than control group ${ }^{[38]}$. In another clinical study, most of the victims of the Tokyo subway sarin attack were found to have long-lasting somatic complaints (such as gastrointestinal problems, constipation, heartburn, nausea, vomiting, colitis, migraines, headaches, backaches, and skin disorders) at 5 - 6 years after poisoning. The long lasting somatic complaints and decreased psychomotor function of the victims exposed to organophosphates may be associated with neuronal damage in the cortex and thalamus ${ }^{[53]}$.

Oxidative stress: In sub chronic or chronic organophosphate exposition induction of oxidative stress has been reported as the main mechanism of organophosphate toxicity ${ }^{[54]}$. Oxidative stress is induced in both acute and chronic intoxication with organophosphate compounds in humans and experimental animals $^{[55]}$. Hyperglycaemia is one of the mechanism of oxidative stress in organophosphate intoxication ${ }^{[56]}$. Studies on chronic exposure to carbamate insecticides and case reports of long-term exposure give equivocal results ${ }^{[57]}$. An extensive survey of the toxicology of the common insecticide, carbaryl, reports a variety of reversible neurobehavioral and neurotoxic effects in vertebrates, all associated with acute poisoning symptoms ${ }^{[58]}$. The carbamate, carbofuran, has been observed to accentuate oxidative stress in rat brain by inducing lipid peroxidation and diminishing the antioxidant defense ${ }^{[59]}$.

Development of cancer: The studies on cancer analyze the risks associated with the consumption of specific products which have some pesticide residues. These consumption products include fish, water, seafood, and milk or other dairy products. In general, these studies find a small but statistically significant association between cancer risks and some specific pesticide residues, such as dichlorodiphenyltrichloroethane and dichlorodiphenyltrichloroethane. Specifically polychlorinated biphenyls present a higher risk for consumers. Organochlorine pesticide residue levels were reported significantly higher in the cancer patients ${ }^{[60-63]}$.

Reproductive disorders: Results indicated that increase of insecticides in blood level in vertebrates causes reproductive dysfunction and suggested that for human beings food like fish, chick and goat containing beyond permissible limit of insecticides must be avoided ${ }^{[64]}$. Consumption of high pesticide residue fruits and vegetables was associated with lower total sperm count, ejaculate volume and percentage of morphologically normal sperm among men attending a fertility clinic ${ }^{[65]}$. Pesticides exposure may lead to reduced fertility, early and late pregnancy loss, prolonged time-to-pregnancy, spontaneous abortion, and premature birth in female and genetic alterations in sperm, re- duced sperm count, damage to germinal epithelium and altered hormone function in male ${ }^{[66]}$.

\section{Preventive measures to reduce pesticide residues in food grains, vegetables, and fruits}

Different types of pesticides are used in different countries for different types of crops to prevent pests, insects, and weeds. Because of the expansion of worldwide trade, more foods which are treated by pesticide are being imported into different countries. These worldwide trades increase the expansion of pesticide residues in different areas of the world and it's the issue of public health concern. There are a number of strategies which can be used to minimize pest and disease problems and reduce pesticide residues in food grains, vegetables and fruits ${ }^{[67]}$.

Organic farming: One of the methods used to reduce the effect of pesticide residue in food is to eat organic foods than non-organic ones. According to standard meta-analyses the frequency of occurrence of detectable pesticide residues was four times higher in non-organic crops than organic crops ${ }^{[68]}$. There is evidence that indicated organic food consumption can reduce exposure to pesticide residues in food ${ }^{[69]}$. Organic crops, on average, have higher concentrations of antioxidants and a lower incidence of pesticide residues than the non-organic foods across regions and production seasons. It is advisable to consume foods rich in antioxidant to reduce effects of the chronic disease by suppressing oxidative activity. An increased dietary intake of antioxidant rich foods protect against chronic diseases, including cardio vascular diseases, certain cancers (e.g. prostate cancer) and neurodegenerative diseases ${ }^{[70]}$.

Washing food products: The second methods reported to reduce pesticide residue in food is washing. Washing may reduce pesticide residue in food commodities. Washing with water and various chemical solutions for domestic and commercial applications is necessary to decrease the pesticide residues. The efficiency of the washing treatments on pesticide removal depends on the washing solution, the chemical properties of the pesticide, the surface area, the nature of the food, the length of time the pesticide is in contact with the food, and the formulation and application method of the pesticide. Usually, the pesticide is lodged in the outer wax-like layers and then moves to the inside, making washing and removal of the pesticides less effective ${ }^{[71,72]}$.

Processing food products: An important factor leading to a reduction of any residues left on crops at harvest are processing treatments such as washing, peeling, canning or cooking that the majority of foods receive prior to consumption ${ }^{[73]}$. Pesticide residue levels in fruit and vegetables may change due to processing, such as peeling, boiling, frying, fermentation, grinding ${ }^{[22]}$. Cooking also reduces pesticide residues in food; boiling may remove $35-60 \%$ of organophosphate residues and $20-25 \%$ of organo chlorines ${ }^{[73]}$. Husking and immersing of fruit and vegetables are reported to reduce pesticide residues especially organophosphates $^{[16]}$.

Rational use of pesticides: Rational use of pesticides involves selection of correct pesticides, dosage rates, dilutions, timing, and frequency of application, treatment intervals, and method of application, precautions, and limitations. Rational use of pesti- 
cides can be useful to reduce pesticide residues in food products. In many cases, there may not be any need of a pesticide, particularly where cultural or biological methods are effective ${ }^{[74]}$.

Use of natural pesticides and biopesticides: Bio-pesticides are biodegradable so no harmful residues are produced and are eco-friendly. Bio-pesticides encompasses a broad array of microbial pesticides, biochemical's derived from micro-organisms and other natural sources that confer protection against pest damage. Some insect repellents can also be used for the prevention of pesticide residues accumulation in the food grains, vegetables and fruits ${ }^{[75]}$. Natural pesticides such as extracts and compounds from neem tree are also very useful for the prevention of pesticide residues accumulation in the food products ${ }^{[76]}$.

Implementation and amendment of pesticide-related laws: In India, the agriculture ministry regulates the manufacture, sale, transport, distribution, export, import and use of pesticides under the Insecticides Act, 1968. Still awaiting Parliamentary approval is the Pesticide Management Bill of 2008, which is meant to replace the Insecticides Act, 1968. The pesticide-related laws should be implemented strictly and amended so as to reduce the cases of pesticide residues in food grains ${ }^{[77]}$.

\section{Conclusion and future perspective}

The excess consumption of pesticides contributes in the accumulation of pesticide residues in food grains and vegetables associated with variety of human health hazards, including damage to central and peripheral nervous systems, cancer, allergies and hypersensitivities, reproductive disorders, and disruption of the immune system. The impact of pesticide residues can be minimized by preventive measures such as rational use of pesticides, washing and proper processing of food products, practising organic farming, use of natural pesticides and bio-pesticides, and strict implementation and amendment of pesticide-related laws.

\section{References}

1) Aktar, M.W., Sengupta, D., Chowdhury, A. Impact of pesticides use in agriculture: their benefits and hazards. (2009) Interdiscip Toxicol. 2(1): 1-12.

Pubmed I Crossref I Others

2) Maksymiv, I. Pesticides: benefits and hazards. (2015) J Vasyl Stefanyk Precarpathian Natl 2(1): 70-76.

Others

3) Gupta, P.K. Pesticide exposure-Indian scene. (2004) Toxicol 198 (1-3): 83-90.

Pubmed I Crossref I Others

4) Ecobichon, D.J. Our changing perspectives on benefit and risks of pesticides: a historical overview. (2000) Neurotoxicol 21(1-2): 211-218. Pubmed I Others

5) Ecobichon, D.J. Pesticide use in developing countries. (2001) Toxicol 160 (1-3): 27-33.

Pubmed I Crossref I Others

6) Cooper, J., Dobson, H. The benefits of pesticides to mankind and the environment. (2007) Crop Prot 26(9): 1337-1348.

Crossref I Others

7) Cerejeira, M.J., Viana, P., Batista, S.,et al. Pesticides in Portuguese surface and ground waters. (2003) Water Res 37(5): 1055-1063.

Pubmed I Crossref I Others

8) Bankar. R., Ray, A.K., Kumar, A., Adeppa, K., et al. Organochlorine pesticide residues in vegetables of three major markets in Uttar Pradesh, India. (2012) Acta Biolog 1(1): 77-80.

Others

9) Puri,P. Food safety assurance through regulation of agricultural pesticide use in India: perspectives and prospects. (2014) J Life Sci 3(2): 123-127.

Others

10) Sachs, J., Remans, R., Smukler, S., et al. Monitoring the world's agriculture. (2010) Nature 466: 558-560.

Pubmed I Crossref I Others

11) Crinnion, W.J., Chlorinated pesticides: threats to health and importance of detection. (2009) Altern Med Rev 14(4): 347-359.

Pubmed I Others

12) Vela, N., Perez, G., Navarro, G. et al. Gas chromatographic determination of pesticide residues in malt, spent grains, wort, and beer with electron capture detection and mass spectrometry. (2007) J AOAC Int 90(2): 544-549.

Pubmed I Others

13) Collins, D.A. A review of alternatives to organophosphorus compounds for the control of storage mites. (2006) J Stored Prod Res 42(4): 395-426.

Crossref I Others

14) Handford, C.E., Elliott, C.T., Campbell, K. A review of the global pesticide legislation and the scale of challenge in reaching the global harmonization of food safety standards. (2015) Integr Environ Assess Manag 11(4): 525-536.

Pubmed I Others

15) Amenze, J.S., Tyohemba, R.L., Ahile, U.J., et al. Organochlorine pesticide residues analysis of postharvest cereal grains in Nasarawa State, Nigeria. (2014) Int J Agron Agri Res 5(5): 59-64.

Others

16) Neme, K, Satheesh, N.Review on pesticide residue in plant food products: health impacts and mechanisms to reduce the residue levels in food. (2016) Arch Appl Sci Res 8(3): 55-60.

17) Ogah, C.O., Coker, H.B., Adepoju-Bello, A.A.Organophosphate and carbamate pesticide residues in beans from markets in Lagos State, Nigeria. (2011) J Inn Res Eng Sciences 2(1): 50-59.

18) Zia, M.S., Khan, M.J., Qasim, M., et al. Pesticide Residue in the Food Chain and Human Body inside Pakistan. (2009) J Chem Soc Pak 31(2): 284-291.

Others 
19) Bajwa, U., Sandhu, K.S. Effect of handling and processing on pesticide residues in food- a review. (2014) J Food Sci Technol 51(2): 201 220.

Pubmed I Crossref I Others

20) Kostik, V., Angelovska, B., Kiroska-Petreska, E., et al. Determination of pesticide residues in plant-based foods from the Republic of Macedonia. (2014) J Food Nut Sci 2(4): 124-129.

Others

21) Petraitis, J., Jarmalaitè, I., Vaičiūnas, V., et al. A review of research studies into pesticide residues in food in Lithuania. (2013) Zemdirbyste-Agri 100: 205-214.

Crossref I Others

22) Claeys, W.L., Schmit, J., Bragard, C., et al. Exposure of several Belgian consumer groups to pesticide residues through fresh fruit and vegetable consumption. (2011) Food Control 22(3-4): 508-516.

Crossref I Others

23) Chen, C.,Qian, Y., Chen, Q., et al. Evaluation of pesticide residues in fruits and vegetables from Xiamen, China. (2011) Food Control 22(7): 1114-1120.

Crossref I Others

24) Reddy, J.D., Rao, N.B., Sultan, A.M. Insecticide Residues in market samples of grape berries. (2000) Pesto 16 (9): 17-22.

Others

25) Mohapatra, S., Sharma, D., Rekha, A. Residues of lambda cyhalothrin in/on acid lime (Citrus aurantifolis). (2006) J Pesti Res 18(1): 74-75.

Others

26) Bhanti, M., Taneja, A. Contamination of vegetables of different seasons with organophosphorus pesticides and related health risk assessment in northern India. (2007) Chemosphere 69(1): 63-68.

Pubmed I Others

27) Agarwal. A., Prajapati, R., Singh, O.P., et al. Pesticide residue in water--a challenging task in India. (2015)Environ Monit Assess 187(2): 54.

Pubmed I Others

28) Bjørling-Poulsen, M., Andersen, H.R., Grandjean, P. Potential developmental neurotoxicity of pesticides used in Europe. (2008) Environ Health 7: 50.

Pubmed I Crossref I Others

29) Damalas, C.A.,Eleftherohorinos, I.G.Pesticide exposure, safety issues, and risk assessment indicators.(2011) Int J Environ Res Public Health 8(5): 1402-1419.

Pubmed I Crossref I Others

30) Selvaraj, S., Basavaraj, B., Hebsur, N.S. Pesticides use and their residues in soil, grains and water of paddy ecosystem - a review. (2014) Agri Rev 35(1): 50-56.

Crossref I Others

31) Boon, P.E., Van der, V. H., Van Raaij, M.T., et al. Cumulative risk assessment of the exposure to organophosphorus and carbamatesinsecticides in the Dutch diet.(2008) Food Chem Toxicol 46(9): 3090-3098. Pubmed I Crossref I Others

32) Mishra, P., Sharma, A., Sharma, D. A study on harmful effects of pesticide residue in vegetables. (2014) Int J Recent Res Rev 7(1): 4548 .

Others

33) Santos, M.D., Pereira, E.F., Aracava, Y., et al. Low concentrations of pyridostigmine prevent soman-induced inhibition of GABAergic transmission in the central nervous system: involvement of muscarinic receptors. (2003) J Pharmacol ExpTher 304: 254-265.

Pubmed I Crossref I Others

34) McDonough, J.H.. Shih, T.M.Neuropharmacological mechanisms of nerve agent-induced seizure and neuropathology. (1997) Neurosci Biobehav Rev 21(5): 559-579.

Pubmed I Crossref I Others

35) Clifford, D.B.,Olney, J.W.,Maniotis, A., et al. The functional anatomy and pathology of lithium-pilocarpine and high-dose pilocarpine seizures. (1987) Neurosci 23(3): 953-968.

Pubmed I Crossref I Others

36) Bhagat, Y.A., Obenaus, A., Hamilton, M.G., et al. Neuroprotection from soman-induced seizures in the rodent: evaluation with diffusionand T2-weighted magnetic resonance imaging. (2005) Neurotoxicol 26(6): 1001-1013.

Pubmed I Crossref I Others

37) Sullivan, P.G., Rabchevsky, A.G., Hicks, R.R., et al. Dose response curve and optimal dosing regimen of cyclosporin A after traumatic brain injury in rats. (2000) Neurosci 101(2): 289-295.

Pubmed I Crossref I Others

38) Gullapalli, R.P., Aracava, Y., Zhuo, J.,et al. Magnetic resonance imaging reveals that galantamine prevents structural brain damage induced by an acute exposure of guinea pigs to soman. (2010) Neurotoxicol 31(1): 67-76.

Pubmed I Crossref I Others

39) Gokel, Y.. Subarachnoid hemorrhage and rhabdomyolysis induced acute renal failure complicating organophosphate intoxication. (2002) Ren Fail 24(6): 867-871.

Pubmed I Crossref I Others

40) Hamilton, M.G., Posavad, C. Alteration of calcium influx in rat cortical synaptosomes by soman. (1991) Neuroreport 2(5): 273-276.

Pubmed I Crossref

41) Pazdernik ,T.L., Emerson,M.R., Cross, R.,et al. Soman-induced seizures: limbic activity, oxidative stress and neuroprotective proteins. (2001) J Appl Toxicol 21(1): S87-S94

Pubmed I Crossref I Others

42) Williams, A.J.,Berti, R., Yao, C., et al. Central neuro-inflammatory gene response following soman exposure in the rat. (2003) Neurosci Lett 349(3): 147-150.

Pubmed I Crossref I Others

43) Siesjo, B.K., Siesjo, P. Mechanisms of secondary brain injury. (1996) J Anaesthesiol 13(3): 247-268.

Pubmed I Crossref I Others

44) Job, A., Baille, V., Dorandeu, F., et al. Distortion product otoacoustic emissions as non-invasive biomarkers and predictors of soman-induced central neurotoxicity: a preliminary study. (2007) Toxicology 238(2-3): 119-129.

Pubmed I Crossref I Others

45) Filliat, P., Baubichon, D., Burckhart, M.F., et al. Memory impairment after soman intoxication in rats: correlation with central neuropathology. Improvement with anticholinergic and antiglutamatergic therapeutics. (1999) Neurotoxicol 20(4): 535-549.

Pubmed

46) Haley, R.W., Kurt, T.L. Self-reported exposure to neurotoxic chemical combinations in the Gulf War: a cross-sectional epidemiologic study. (1997) JAMA 277(3): 231-237.

Pubmed I Crossref I Others

47) Proctor, S.P., Heaton K.J., Heeren, T., et al. Effects of sarin and cyclosarin exposure during the 1991 Gulf War on neurobehavioral functioning in US army veterans. (2006) Neurotoxicology 27(6): 931-939. Pubmed I Crossref I Others

48) Satoh, T., Hosokawa, M. Organophosphates and their impact on the global environment. (2000) Neurotoxicol 21(1-2): 223-227. Pubmed

49) Yokoyama, K., Araki, S., Murata, K., et al. Chronic neurobehavioral effects of Tokyo subway sarin poisoning in relation to posttraumatic stress disorder. (1998) Arch Environ Health 53(4): 249-256.

Pubmed I Crossref I Others

50) Hoffman, A., Eisenkraft, A., Finkelstein, A., et al. A decade after the Tokyo sarin attack: a review of neurological follow-up of the victims. (2007) Mil Med. 172(6): 607-610.

Pubmed I Crossref

51) Hatta, K., Miura, Y., Asukai, N., et al. Amnesia from sarin poisoning. (1996) Lancet 347(9011): 1343.

Pubmed I Crossref I Others 
52) Morris, R. Developments of a water-maze procedure for studying spatial learning in the rat. (1984) J Neurosci Meth 11(1): 47-60.

Pubmed I Crossref I Others

53) Nozaki, H., Aikawa, N., Shinozawa, Y., et al. Sarin poisoning on Tokyo subway. (1995) Lancet 345(8955): 980-981.

Crossref I Others

54) Ranjbar, A., Solhi, H., Mashayekhi, F.J., et al. Oxidative stress in acute human poisoning with organophosphorus insecticides; a case control study. (2005) Environ Toxicol Pharmacol 20(1): 88-91.

Pubmed I Crossref I Others

55) Abdollahi, M., Rainba, A., Shadnia, S., et al. Pesticide and oxidative stress: a review. (2004) Med Sci Monitor 10(6): RA141-RA147. Pubmed I Others

56) Rahimi, R., Nikfar, S., Abdollahi, M. Increased morbidity and mortality in acute human organophosphate-poisoned patients treated by oximes: a meta-analysis of clinical trials. (2006) Hum Exp Toxicol 25(3): 157-162

Pubmed I Crossref I Others

57) Dickoff, D.J., Gerber, O., Turovsky, Z. Delayed neurotoxicity after ingestion of carbamate pesticide. (1987) Neuro 37(7): 1229-1231

Pubmed I Crossref I Others

58) Cranmer, M.F. Carbaryla toxicological review and risk analysis. (1986) Neurotoxicol 7(1): 247-328.

Pubmed I Others

59) Kamboj, A., Kiran, R., Sandhir, R. Carbofuran-induced neurochemical and neurobehavioral alterations in rats: attenuation by $\mathrm{N}$-acetylcysteine. (2006) Exp Brain Res 170(4): 567-575.

Pubmed I Crossref I Others

60) Li, X., Gan, Y., Yang, X.,et al. Human health risk of organochlorine pesticides (OCPs) and polychlorinated biphenyls (PCBs) in edible fish from Huairou Reservoir and Gaobeidian Lake in Beijing, China. (2008) Food Chem 109(1): 348-354.

Pubmed I Crossref I Others

61) Moon, H.B., Kim, H.S., Choi, M., et al. Human health risk of polychlorinated biphenyls and organochlorine pesticides resulting from seafood consumption in South Korea, 2005-2007. (2009) Food Chem Toxicol 47(1): 1819-1825.

Pubmed I Crossref I Others

62) Pandit, G.G., Sahu, S.K., Assessment of risk to public health posed by persistent organochlorine pesticide residues in milk and milk products in Mumbai, India. (2002) J Environ Monit 4(1): 182-185.

Pubmed I Crossref I Others

63) Mathur, V., John, P.J., Soni, I., et al. Blood levels of organochlorine pesticide residues and risk of reproductive tract cancer among women from Jaipur, India. (2008) Adv Exp Med Bio 617: 387-394.

Pubmed I Crossref I Others
64) Singh, P.B., Singh, V., Nayak, P.K. Pesticide residues and reproductive dysfunction in different vertebrates from north India. (2008) Food Chem Toxicol 46(7): 2533-2539.

Pubmed I Crossref I Others

65) Chiu, Y.H., Afeiche, M.C., Gaskins, A.J., et al. Fruit and vegetable intake and their pesticide residues in relation to semen quality among men from a fertility clinic. (2015) Hum Reprod 30(6): 1342-1351.

Pubmed I Crossrefl Others

66) Bretveld, R.W., Thomas, C.M., Scheepers, P.T., et al. Pesticide exposure: the hormonal function of the female reproductive system disrupted? (2006) Reprod Biol Endocrinol 4: 30.

Pubmed I Crossref I Others

67) Gale, F.,Buzby, J.C.Imports from China and food safety issues. (2009) Eco Inf Bul 52: 1-37.

Others

68) Baranski, M., Srednicka-Tober, D., Volakakis, N., et al. Higher antioxidant and lower cadmium concentrations and lower incidence of pesticide residues in organically grown crops: a systematic literature review and meta-analyses. (2014) Bri J Nutr 112(5): 794-811.

Pubmed I Crossref I Others

69) Smith-Spangler, C., Brandeau, M.L., Hunter, G.E., et al. Are organic foods safer or healthier than conventional alternatives?: a systematic review. (2012) Ann Intern Med 157(5): 348-366.

Pubmed I Crossref I Others

70) Wahlqvist, M.L., Antioxidant relevance to human health. (2013) Asia Pac J Clin Nutr 22(2): 171-179.

Pubmed

71) Bull, D.. A growing problem: pesticides and the third world poor. (1982) Oxford.

Others

72) Al-Taher, F., Chen, Y., Cappozzo, J. Reduction of pesticide residues in tomatoes and other produce. (2013) J Food Prot 76(3): 510-515.

Pubmed I Crossref I Others

73) Holland,P.T., Hamilton, D., Ohlin, B., et al. Pesticides report 31: effects of storage and processing on pesticide residues in plant products (technical report). (1994) Pure Appl Chem 66(2): 335-346.

Crossref

74) Mukunya, D.M., Muinamia, C. Rational use of pesticides in horticulture with special emphasis onKenya. (1988) Acta Hortic 218: 261266.

Crossref

75) Gupta, S.,Dikshit, A.K., Biopesticides: An eco-friendly approach for pest control. (2010) J Biopest 3(1): 186-188.

Others

76) Schmutterer, H. Properties and potential of natural pesticides from the neem tree, AzadirachtaIndica. (1990) Ann Rev Entomol 35: 271297.

Pubmed I Crossref I Others

77) Sharma, E.K. How effective is pesticide regulation in India? (2017). Others
Ommega Online Publisher

Journal of Medicinal Chemistry \& Toxicology

Short Title : J Med Chem Toxicol
E-mail: medchemtoxic@ommegaonline.org

website: www.ommegaonline.org 